\title{
STANDARDS - AN IMPORTANT STEP FOR THE (PUBLIC) USE OF LIDARS
}

\author{
Dietrich Althausen ${ }^{1 *}$, Stefan Emeis ${ }^{2}$, Harald Flentje ${ }^{3}$, Josef Guttenberger ${ }^{4}$, \\ Simon Jäckel ${ }^{5}$, Volker Lehmann ${ }^{6}$, Ina Mattis ${ }^{3}$, Christoph Münkel ${ }^{7}$, \\ Gerhard Peters ${ }^{8}$, Christoph Ritter ${ }^{9}$, Matthias Wiegner ${ }^{10}$, Holger Wille ${ }^{11}$ \\ ${ }^{1}$ Leibniz Institute for Troposheric Research, 04318 Leipzig, Germany, *Email: dietrich@tropos.de \\ ${ }^{2}$ Karlsruhe Institute of Technology (KIT), 82467 Garmisch-Partenkirchen, Germany \\ ${ }^{3}$ Deutscher Wetterdienst, 82383 Hohenpreissenberg, Germany \\ ${ }^{4}$ RSC GmbH, 92355 Velburg, Germany \\ ${ }^{5}$ Commission on Air Pollution Prevention (KRdL) of VDI and DIN, 40468 Düsseldorf \\ ${ }^{6}$ Deutscher Wetterdienst, 15848 Tauche OT Lindenberg, Germany \\ ${ }^{7}$ Vaisala GmbH, 22607 Hamburg, Germany \\ ${ }^{8}$ METEK Meteorologische Messtechnik GmbH, 25337 Elmshorn, Germany \\ ${ }^{9}$ Alfred Wegener Institute, Helmholtz Centre for Polar and Marine Research, 14401 Potsdam, Germany \\ ${ }^{10}$ Ludwig-Maximilians-Universität, 80333 München, Germany \\ ${ }^{11}$ G. Lufft Mess- und Regeltechnik GmbH, 12489 Berlin, Germany
}

\begin{abstract}
Lidar standards are needed to ensure quality and lidar product control at the interface between lidar manufacturers and lidar users. Meanwhile three lidar standards have been published by German and international standardization organizations. This paper describes the cooperation between the lidar technique inventors, lidar instrument constructors, and lidar product users to establish useful standards. Presently a backscatter lidar standard is elaborated in Germany. Key points of this standard are presented here. Two German standards were already accepted as international standards by the International Organization for Standardization (ISO). Hence, German and international organizations for the establishment of lidar standards are introduced to encourage a cooperative work on lidar standards by lidar scientists.
\end{abstract}

\section{INTRODUCTION}

Aerosol lidar instruments get more and more applied for public and broad-scale purposes (compare for instance the ceilometer networks and the GAW Aerosol Lidar Observations Network GALION: [1,2]). This can be understood as a step out of the lab by the researchers to combine synergistically measurements within lidar networks (e.g. [3]). With establishing lidar networks, the quality assurance and quality control and hence the standards of the systems need to be regarded comprehensively.

There is a steady need of improving the public health by taking into account research results and the recognition of their application. This was especially recognized during the eruption of the Eyjafjallajökull volcano in 2010 when only lidar measurements could provide information about the vertical extend of the plume and its ash concentrations (compare e.g. results from these measurements in [4]). Such events increase the awareness of the public to implement lidar systems that have been manufactured according to internationally accepted standards. Only then, measurements can be combined for continental or even global surveillance. 


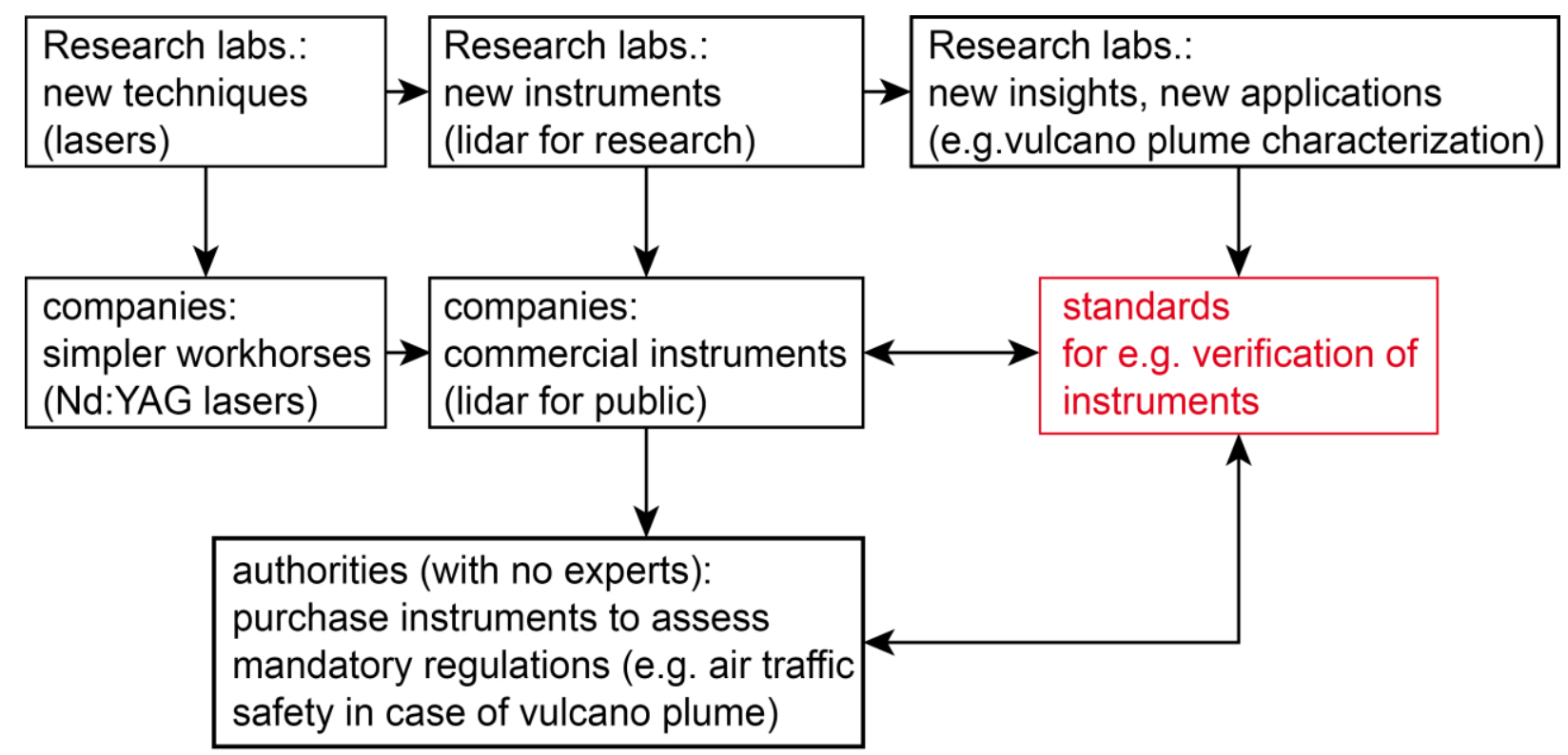

Fig.1: Schematic sketch about the cooperation of lidar scientists, lidar technicians, and lidar users that yields to the need of standards about lidars. The volcano case is mentioned as an example that has forced the work on standards.

So there is a need for standards that can be used by the manufacturers and users to understand each other.

Meanwhile three standards for lidar applications have been published by German and international standardization organizations [5-7]. Presently the responsible board in Germany deals with a standard regarding backscatter lidar.

This paper explains the cooperation that yields to standards in chapter 2 . The current status of the standard regarding backscatter lidar is explained in chapter 3. The standard developing work is done in selected expert groups that are introduced in chapter 4. At the end of the paper the main ideas are summarized and an outlook is given.

\section{COOPERATION OF LIDAR TECHNIQUE INVENTORS, LIDAR INSTRUMENT CONSTRUCTORS, AND LIDAR PRODUCT USERS}

Figure 1 shows a schematic sketch of the cooperation between lidar scientists, lidar technicians, and lidar users for establishing standards.

Looking back, lidar systems were developed and after this (independent of this) the laser was invented. The application of lasers in lidars was a big step forward for the development and improvement of different lidar types (e.g. backscatter lidar, differential absorption lidar, Raman lidar, high-spectral-resolution lidar) and their application for atmospheric research purposes by research institutes. One recent example of such new atmospheric insights is the estimation of mass concentrations in the plume advected over Europe from the Icelandic volcano Eyjafjallajökull in 2010 (e.g. [8]).

Parallel to these research activities companies were founded for manufacturing lidar systems. At the beginning, the products of these lidar companies were only used by research institutes that have experts and know how to handle the systems. With time, smaller and "plug and play" lidar systems are offered by these companies due to the development of e.g. smaller and cheaper lasers.

With the research results, authorities realized the successful application of lidar systems to monitor specific atmospheric events (e.g., plumes from volcanic eruptions) and the benefit to their work for e.g. regulations of air quality. As a consequence, national weather services started to purchase smaller lidars, too. 
This development yields directly to define standards about lidar systems and their products / output for public use.

The interest of the researchers to contribute to the development of these standards is that they often work in governmental funded institutes. Also helping writing they get applied their results.

The interest of the public (authorities) having such standards is that they can use the lidar systems for their purposes as for instance a better knowledge about the air quality. By this they can reduce or even avoid risks and severe situations.

The interest of the companies on these standards is that they get a document that can be referred to when offering their products.

These standards help the lidar manufacturers to offer their systems to authorities and help the authorities to purchase such systems since the standards can be used for e.g. system verification. So the standards define a quality and help the quality control, make systems comparable, and show the minimum the systems have to provide.

\section{EXAMPLE: STANDARD REGARDING BACKSCATTER LIDAR}

Presently the standard regarding the backscatter lidar is compiled in Germany. The goal is to publish the first draft beginning 2016. So all information about this standard is still preliminary.

The standard consists of 11 chapters and 1 appendix. The topics include area of application, references to other standards, basics of backscatter lidar, target quantities and operation properties, system components, planning of a measurement and requirements to the measurement site, influencing quantities and considerations to uncertainties, quality assurance and system control, and examples of measurements. Appendix A summarizes some of the information the manufactures have to provide to the data users for the data retrieval algorithms. It is not possible to describe all chapters in detail within this paper. So, only remarks to 3 chapters will be presented below.

Chapter 1 summarizes possible application areas of a backscatter lidar. This shows also possible customers of the standard. These application areas are for instance detection of atmospheric particle layers and/or cloud boundaries, derivation of profiles of the particle backscatter coefficient, estimates of size and/or shape classification of particles, monitoring of the air quality, and contributions to air traffic safety, weather forecast, satellite remote sensing.

The theoretical basis of an (elastically) backscatter lidar is described in chapter 5 . The lidar equation is given after the main features / system parts of a backscatter lidar. Several considerations are made: choice of wavelength, attenuated backscatter coefficient, particle backscatter coefficient, retrieval method by Klett and Fernald, determination of reference values and/or boundary values, retrievals using system constants, particle extinction coefficient, depolarization ratio, Ångström exponent, and color ratio.

An overview of the primary and derived quantities is given in chapter 6 . The range-corrected backscatter signal, the attenuated backscatter coefficient and the particle backscatter coefficient are defined as the primary target quantities of a backscatter lidar. Derived quantities are boundaries of atmospheric particle layers, cloud heights and vertical extensions, and the shape classification of particle layers (with the linear depolarization ratio). Auxiliary quantities as the air density required to apply the Klett-Fernald formalism are regarded in chapter 6 , too. The operation properties are explained by describing quantities like signal-to-noise ratio, temporal resolution, range resolution, range averaging, overlap function, range of measurement, data availability, and range of coverage for certain conditions. Especially the range of coverage makes a comparison of different systems possible.

\section{NATIONAL AND INTERNATIONAL BOARDS FOR LIDAR STANDARDS}

In Germany two institutions are responsible for the standardization in the field of meteorology: DIN (German Institute for Standardization; Deutsches Institut für Normung e. V.; [9]) and VDI (The Association of German Engineers; Verein Deutscher Ingenieure e.V.; [10]). They work together in the Commission on Air Pollution Prevention (KRdL; [11]). One department of $\mathrm{KRdL}$ is responsible for the elaboration of 
standards on environmental meteorology, which includes meteorological measurements.

DIN is the German representative in the International Organization for Standardization (ISO). ISO is an independent, non-governmental organization of members from the national standardization bodies of 163 countries [12]. Each technical committee (TC) of ISO - e.g. ISO/TC 146 "Air quality" - has a mirror board at DIN. The subcommittee (SC) 5 of TC 146 deals with meteorology. Presently there are 17 participating and 10 observing countries in ISO/TC 146/SC 5. The steering committee of KRdL department on environmental meteorology is the mirror board for ISO standards regarding meteorological measurements. This structure is organized in the same way in all participating countries of SC5.

The standardization projects of ISO/TC 146/SC 5 are elaborated in cooperation with the World Meteorological Organization (WMO) through its Technical Commission on Instruments and Methods of Observation (CIMO).

\section{CONCLUSION AND OUTLOOK}

An increasing number of commercial lidars systems is available and applied in lidar networks. Most likely, lidars will soon be used by institutions without lidar experts. Hence, standards for the systems and their possible products need to be elaborated.

The provision of a standard for the most basic lidar concept, the backscatter lidar, shows that efforts are necessary to extend the standardization work to more complex lidar techniques as for instance the Raman technique.

The lidar technique is an international technique and the atmosphere is per se a common good. So there is a strong need that lidar scientists work on international lidar standards.

\section{REFERENCES}

[1] http://www.dwd.de/ceilomap (05 June 2015).

[2]

ftp://ftp.wmo.int/Documents/PublicWeb/arep/gaw /gaw178-galion-27-Oct.pdf (05 June 2015).

[3] Pappalardo, G., A. Amodeo, A. Apituley, A. Comeron, V. Freudenthaler, H. Linné, A. Ansmann, J. Bösenberg, G. D'Amico, I. Mattis, L.
Mona, U. Wandinger, V. Amiridis, L. AladosArboledas, D. Nicolae, and M. Wiegner, 2014: EARLINET: towards an advanced sustainable European aerosol lidar network, Atmos. Meas. Tech., 7, 2389-2409, doi:10.5194/amt-7-23892014

[4] Ansmann, A., M. Tesche, P. Seifert, S. Groß, V. Freudenthaler, A. Apituley, K. M. Wilson, I. Serikov, H. Linné, B. Heinold, A. Hiebsch, F. Schnell, J. Schmidt, I. Mattis, U. Wandinger, and M. Wiegner, 2011: Ash and fine-mode particle mass profiles from EARLINET-AERONET observations over central Europe after the eruptions of the Eyjafjallajökull volcano in 2010, J. Geophys. Res., 116, D00U02, doi:10.1029/2010JD015567.

[5] VDI 4210 Part 1, 1999: Remote sensingAtmospheric measurements with LIDAR Measuring gaseous air pollution with DAS LIDAR. German/English. Beuth Verlag, Berlin, $47 \mathrm{p}$.

[6] ISO 28902-1, 2012: Air qualityEnvironmental meteorology - Part 1: Groundbased remote sensing of visual range by lidar.

[7] ISO/DIS 28902-2, 2015: Air quality Environmental meteorology - Part 2: Groundbased remote sensing of wind by heterodyne pulsed Doppler lidar.

[8] Wiegner, M., J. Gasteiger, S. Groß, F. Schnell, V. Freudenthaler, and R. Forkel, 2012: Characterization of the Eyjafjallajökull ashplume, 2012: Potential of lidar remote sensing, J Phys. Chem. Earth, 45-46, p 79-86, doi: 10.1016/j.pce.2011.01.006.

[9] http://www.din.com (05 June 2015).

[10] http://www.vdi.eu (05 June 2015).

[11] http://www.vdi.eu/krdl (05 June 2015).

[12] http://www.iso.org (05 June 2015). 